
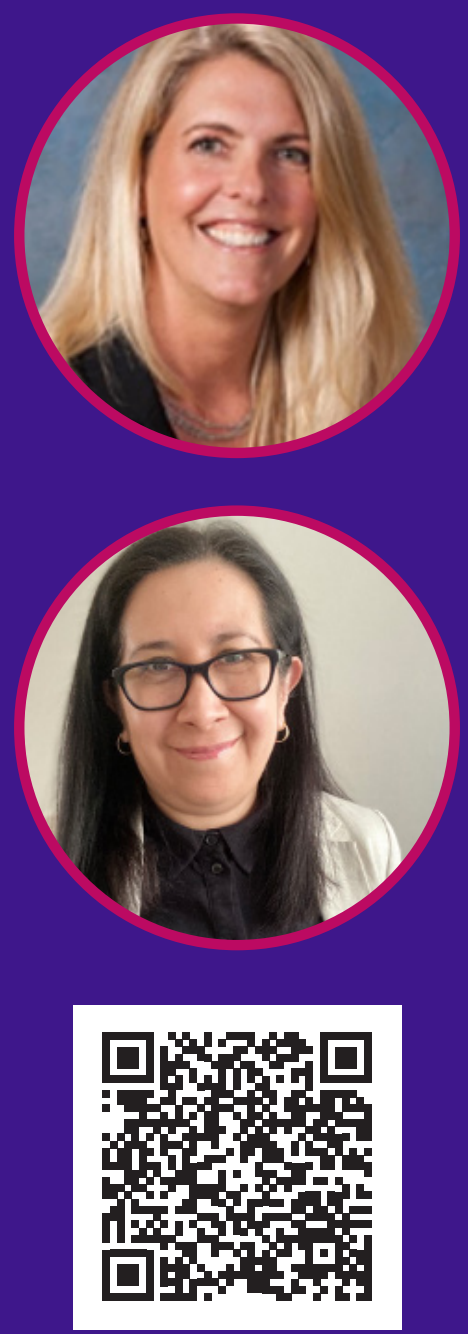

Videopresentación

\title{
Interuniversity Global Student Collaboration During COVID-19
}

\author{
Colaboración estudiantil global interuniversitaria durante \\ COVID-19
}

\author{
Dr. Mindy Magrane \\ Northwestern University, Chicago, USA \\ mindy.magrane@northwestern.edu
}

Recibido: 12 de marzo de 2021.

Aceptado: 27 de marzo de 2021.

Publicado: 31 de mayo de 2021.

\author{
Mtra. Mariana Garduño \\ Universidad Panamericana, campus \\ México \\ Igarduno@up.edu.mx
}

Received: March 12th, 2021.

Accepted: March 27th, 2021.

Published: May 31st, 2021.

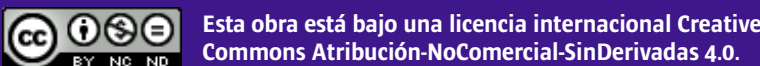

\section{DoI: https://doi.org/10.21555/rpc.voi1.2359}

Cómo citar: Magrane, M. ., \& Garduño, M. . . (2021). Colaboración estudiantil global interuniversitaria durante COVID-19. RPC, (1), 144-153. https://doi.org/10.21555/rpc.v0i1.2359

Revista Panamericana de Comunicación, Año 3, N. 1, enero-julio 2021, pp. 144-153.

\section{ABSTRACT}

During the spring of 2020, schools and universities across the world were among the institutions that had to close down their activities due to the COVID-19 lockdown. Because of its high level of contagion, students and faculty were prevented from having regular on-site synchronous classes. Innovative and virtual learning projects were designed to continue amid the pandemic. In order to provide students with novel, digital, collaborative experiences that enhanced their particular course learning outcomes, a two- 
week global teaming activity between two different universities (located in Illinois, U.S.A. and Mexico City, Mexico) was designed and implemented during the lockdown. The technical tools, digital environments, expected skill development and resources were set during the design period including a theoretical framework from which students were able to address and engage during the activity. Once the activity took place, the results obtained from the experience varied from the use and acquired skills from collaborative, real-time technological tools, to different approaches to problem-solving between the participating teams and finally the way that cultural, language and generational differences played out during the teaming activity, between students and faculty members.

Keywords: Teaming activity, on line, Northwestern University, Universidad Panamericana.

\section{RESUMEN}

Durante la primavera de 2020 , escuelas y universidades alrededor del mundo se encontraron dentro de las instituciones que tuvieron que suspender sus actividades derivado del cierre por COVID-19. Debido a su alto nivel de contagio, alumnos y profesores fueron pre- venidos de tener clases síncronas presenciales regulares. Para continuar en medio de la pandemia, se diseñaron proyectos de aprendizaje innovadores y virtuales. Con el fin de proveer a los alumnos con experiencias novedosas, digitales y colaborativas que mejoraran los resultados de aprendizajes de sus cursos en particular, se diseñó e implementó durante el cierre de emergencia sanitaria, una actividad de equipos globales, entre dos universidades (ubicadas en Illinois, EE. UU. y la Ciudad de México, México) con duración de dos semanas. Las herramientas tecnológicas, ambientes digitales, recursos y habilidades a desarrollar esperadas fueron establecidas durante el periodo de diseño incluyendo un marco teórico desde el cual los estudiantes fueron capaces de llevar a cabo e involucrarse durante la actividad. Una vez que la actividad se llevó a cabo, los resultados obtenidos de la experiencia variaron en su uso y habilidades adquiridas, de las herramientas colaborativas y en tiempo real, a los diferentes acercamientos a la resolución de problemas en los equipos participantes, a finalmente la forma en la que las diferencias culturales, generacionales y de idioma tuvieron un papel durante la actividad, tanto entre los estudiantes como los profesores.

Palabras clave: Trabajo en equipo, en línea, Northwestern University, Universidad Panamericana, COVID-19.

\section{PROJECT AND COLLABORATION OVERVIEW}

This partnership between Northwestern University and Universidad Panamericana was created to provide students with an experience of global teaming and cross-cultural collaboration. Fifteen student teams were created, each consisting of 4-5 students with roughly half from each university. These teams met virtually for a two-hour meeting in November 2020. In this meeting they 1) participated in an ice-breaker to learn more about each other and their respective cultures, 2) creat- ed a design concept for an artificial intelligence device that could aid their families in the near future, and 3) debriefed their process observations of their cross-cultural teaming experience. In-class debriefs of the experience were conducted by both professors. A final individual paper was also due where students were asked to reflect on their team's process, applying concepts from the readings, and their own lessons learned.

The partnership and collaboration took place amid the COVID-19 lockdown in 2020 that started in early March and continued throughout 2020, shift- 
ing from physical classrooms to virtual environments around the world. The following paper describes the project designed to implement a collaborative and global teaming learning experience for both universities' students.

\section{ABOUT NORTHWESTER UNIVERSITY AND UNIVERSIDAD PANAMERICANA}

Universidad Panamericana (UP) is a Mexican private university founded in 1967 as a business school, pointing towards academic excellence, research and teaching. The School of Communication, located in Mexico City, has celebrated its first 20 years and has a prime role in the preparation of future communicators that lead through social impact. The Advertising Innovation class is an undergraduate course for senior students of the Communications program.

Northwestern University (NU) is a private university founded in 1851 and located in Evanston, IL USA. Northwestern is committed to excellent teaching, innovative research and the personal and intellectual growth of its students in a diverse academic community. The Team Dynamics course is located within the School of Education and Social Policy. The school is dedicated to making lives better across individuals, families, organizations, and communities and develops its students to influence change across systems. In the Team Dynamics course, students explore those forces that influence a team's behavior and performance and can enhance or hinder potential for impact.

\section{DESIGNING A COLLABORATIVE GLOBAL PROJECT FOR A VIRTUAL TEACHING AND LEARNING ENVIRONMENT}

The objective for the collaboration was to foster online global team collaboration between Northwestern University and Universidad Panamericana during the COVID-19 lockdown as part of the academic activities for each program in which students and faculty integrate new technologies and project based learning strategies for online learning environments.
The project was designed, developed and implemented by professors from each course from Northwestern University (School of Education and Social Policy, Class: Team Dynamics; 35 undergraduate students) and Universidad Panamericana (School of Communication, Class: Advertising Innovation; 33 undergraduate students) for a total of 68 students.

The global teaming activity developed and implemented though the 2020 COVID-19 pandemic, utilized a specific framework, in which both faculty and students were required to understand and collaborate through two specific scenarios:

» successful teaming and collaboration from cross-cultural and thematic backgrounds, and

» designing and creating a specific project through which students would be led to solve a technological problem and reflect on their own team dynamics for the assignment.

The faculty team from both universities worked with Hofstede cultural dimensions and provided students with electronic resources for their own investigation. As a part of the design framework common to both classes, team dynamics and creativity were part of the reading resources and pre-work provided to students in advance of their collaboration.

Given that collaborating cross-culturally was novel to most students, Hofstede's cultural dimensions were introduced as a framework to enhance 1) awareness of self and one's own cultural proclivities, 2) empathy for differences across culture, and 3) understanding the impact of cultural values on working relationships. Three of these cultural dimensions (Power Distance Index, Individualism vs. Collectivism, and Uncertainty Avoidance Index) were specifically highlighted for this project as Hofstede's research indicates the largest relative difference for these preferences between Mexico and the United States.

A second framework addressed team dynamics. In addition to the dynamics created from team members' individual personalities, how team members navigate their team processes contributes to the 
dynamics that uniquely manifest in each teaming experience as well as the success of the teaming endeavor. To enhance awareness of these influences, students were asked to consider what helped and what hindered team success. Specifically, they explored the following team processes:

» leadership - how leadership emerged and was enacted

» creativity - what helped the team be creative

» inclusivity - how ideas were surfaced and whose ideas were heard

» decision-making - whose ideas carried weight and how the team decided

» communication - the effectiveness of team communication, especially given cross-cultural dynamics, language differences, and virtual teaming

» reflexivity - what the individuals on the team learned about themselves, each other, and the teaming process

Finally, as part of the activity, students were presented with a technological problem that had to be solved through an understanding of people's needs and motivations, beginning with their own points of view. This final approach allowed students to frame their own creativity processes in which their group engaged in discussion to select the most adequate idea to develop during the meeting. As a team, students elaborated on their project through use of:

» creativity skills - both individual and as a team for brainstorming continuity

» openness to others points of view - how ideas grow from collaboration

» assertive communication - how ideas are presented to each other
» agreeableness - which and how concepts are approved or dismissed

» idea integration for further development - how designs take on different features to be completed

» visualization - what needs to be shown for the draft concept pitch

To start the collaboration between both universities and define the project, faculty members started working on the global teaming collaboration early in September 2020 (Fall term for Northwestern University / Winter term for Universidad Panamericana), 5 months after the COVID-19 lockdown started in both the United States and Mexico, and 2 months prior to launching the project with the students.

Faculty members established and held 60-minute periodical meetings in order to complete each of the steps defined with anticipation. In each of these meetings, faculty members discussed: objectives for each of the activities in the project, possible setbacks for the project, and technological assets needed to complete the activities.

Since the classes taught by each member, as well as the students' background did not have a common ground, the project required that the students work on a problem where they could come up with solutions, while taking advantage of their undergraduate program (Advertising Innovation and Team Dynamics). For this, the students would be required to brainstorm as a team and come up with a new and innovative robot (automated assistant) that solved a specific problem to be addressed for different households.

Students from each university would team up randomly during an international collaboration week between universities. Once finished, students were expected to deliver and debrief their current experience with their own teacher and fellow classmates.

Faculty explained the collaboration to students beginning several weeks before the experience which gave them a chance to air their feelings and concerns about it. Some were excited, most were anxious 
about issues like language barriers. Talking about these fears helped with engagement. Faculty also contextualized the experience as to why it was important and how it related to what they were learning in both classes and their future work experiences.

Discussion and agreement on the following elements in advance of the collaboration provided a shared structure for all students which fostered project success:

1. Integration with class syllabus

a. Similar number of students for each class to assure parity

b. Same activities for each class in order to have a cohesive result

c. Synced calendar for the whole activity that all students could comply with

d. Shared team evidences to be evaluated for each class

2. Defining project requirements

a. Problem to be solved (project based learning / PBL)

b. Brief to be discussed with students

c. Technological tools to be used by students

d. Deliverables for each university's LMS (learning management system)

Due to the COVID-19 2020 lockdown, students were attending their classes in an online environment, which by the end of September they were more familiar with than 6 months before. Since both universities had a different term duration, it was agreed to have the activity be in mid November, where respective themes in
Advertising Innovation and Team Dynamics coincided (collaboration and creativity, respectively). This allowed sufficient time for the students to prepare, and for ensuring all the technological resources and tools were uploaded and in full operation.

Faculty members began designing the students' brief, which contained in full description, the step by step instructions they needed to fulfill in order to conduct the exercise. The brief contained links to the online resources students should consult prior to meeting with their team members, a brief description of the project, both universities and the integration expected between students, as well as the readings they had to prepare in order to study Hofstede's cultural dimensions and views on creative concept selection.

In this brief, faculty members shared views on what needed to be achieved and evaluated by the students, considering they would have a specified amount of time to complete the challenge and reflect on their own learnings. The same communication about specifics of the teaming assignment was given to both NU and UP students. Faculty each delivered this differently, but communicated the same content, which helped with alignment. The students' brief was uploaded to each university LMS platform (Moodle and Canvas) for the students to consult.

For the online practice, an online environment for the whole activity needed to be specified and applied considering both Universities had access to different platforms and tools, as well as IT specifications for outside users meeting ownership.

For the learning management system (LMS), each university continued to use their own already set by their administrators. For Northwestern University, Canvas; as for Universidad Panamericana, the LMS used is Moodle. Both allow students to view each course independently, while having access to different activities and tools such as calendars, homework, online workshops and forums, as well as grading books and feedback.

The second tool provided to students for the activity, was a virtual scheduling file, shared via Google Drive. This file contained a predetermined schedule of team meeting times, number of participants for each team, and indications on how many students per university each team should have. 
The third tool to use, would be the video conferencing platform in which the students would team up during the exercise. The selected platform was Zoom Meetings. Students were given a unique Zoom meeting ID according to each scheduled day / hour. Zoom was selected at the time as it provided an easier way to share the link for the videoconference and set up times with access permissions that would be granted and managed by IT from Northwestern University.

Once the schedule was defined, the teams were ready to begin working. The final schedule included 15 teams with 4 to 5 members each. The design previously drafted allowed equal pairing from each university: 1 ) 5 teams with NU majority, 2) 5 teams with UP majority and, 3) 5 teams with equal number of members.

\section{THE COLLABORATION IN ACTION WITH STUDENTS}

Once the design process was finished, faculty briefed the students in each class. This briefing would include the project description, LMS system, scheduling, technological tools, as well as the explanation regarding the shared file with the teams and dates, and finally Q\&A with the students, where they expressed their concerns and expectations for the global teaming activity.

Students were provided very clear written instructions along with a specific goal and agenda. This helped them have a successful experience and helped to contain their anxiety. It minimized conflict over task definition and had the added benefit of helping them see the place of an agenda in a well-run meeting.

Since the instruction was open and clear enough for them, students were observed to team up by: time preference, and for a few students by teaming up based on people they felt more confident working with, due to novelty of the activity. Students got to choose between different schedules (morning, noon and evening). Once the students were all signed up, they were ready to begin the activity in the first week of November.

The activity was held for a whole week in November, 2020. The students teamed up according to the schedule, in groups from 4-5 students for 120 minutes. The experience began with everybody onboard and fol- lowing the agenda and instructions downloaded from the LMS.

Professors were not present in the meetings and did not require that the entire meeting be recorded. This gave students more freedom to create and experiment together. However, students were required to record the last 15 minutes where they answered some debrief questions about their team process and experience - this was part of the assignment and did ensure participation. According to the follow up made with each team, students had no trouble in focusing on the activity (design problem, pitch and their own team reflection) and in some cases even finished earlier than expected.

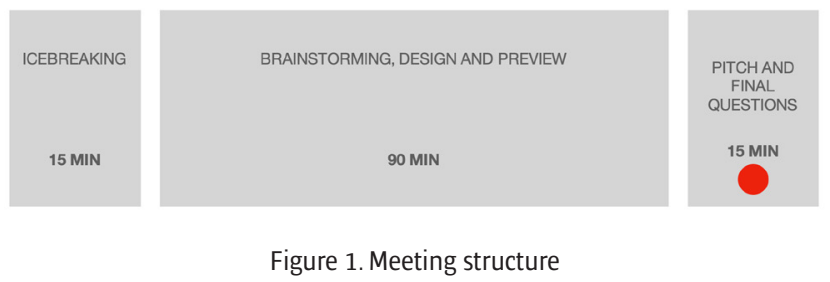

For most teams, English was the agreed upon language for the activity, even though some NU students were eager to practice their own Spanish. Regarding the use of technology, most of the teams were able to connect on time and work with Zoom. Only a couple of teams reported troubleshooting for the permissions and ownership of the meeting, which led them to not being able to produce a final recording of the session.

During the whole week, professors were available for students via e-mail and DMs for assistance and troubleshooting.

Once the activity was finished, students were required to present a total of three pieces of evidence for their own classes in order to evaluate and review the activity, from a personal and team view, aligned to each class's learning outcomes.

1. Visual draft for the household automated assistant regarding problem solving and concept selection (Figure 2) 
2. 15-minute recording with personal and team reflection based on the question guide provided in the LMS

3. 500-word essay on their own experience regarding global teaming

The first two evidences were automatically sent to the Northwestern server via Zoom meetings and later shared with Universidad Panamericana. The third evidence was uploaded by each student directly to their online LMS course in each university for evaluation.
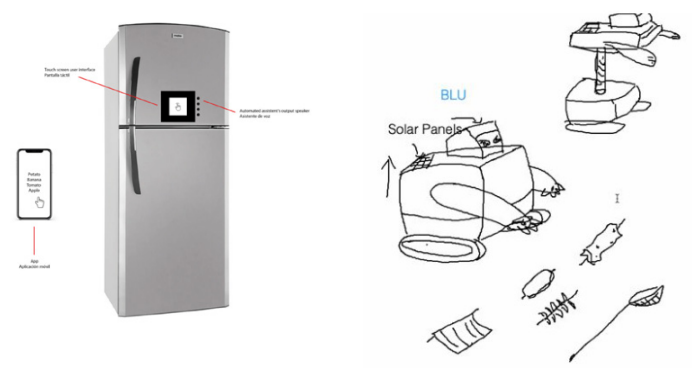

Figure 2. Whiteboard teaming examples for the exercise

Debriefing activities were defined for the next classes in both universities, in order to review the results of the teaming sessions for the whole week. These debriefings allowed for deeper conversation with students about their own learnings, project solving and teaming findings with students from another university and another country, as well the use of new and known technology for the assignment.

Both classes had an in-class discussion the week following the last global team meeting (team 15). Main themes the students brought up were:

1. Reality vs expectation. Students corroborated their own technological skills to complete the task and fluency in English as a second language in the case of UP students.
2. Syllabus integration. Students recognized the faculty work in the previous week to plan and design the activity, considering the necessary and appropriate tools (Zoom, Drive and activity within each LMS) as part of the success in their own meetings.

3. Hofstede dimensions experienced first-hand. Students got the chance to compare in a real world scenario the different cultural dimensions and compare them with their fellow team mates.

\section{LEARNINGS, OUTCOMES AND KEY FINDINGS FOR FUTURE COLLABORATIONS}

Once the project was briefed again between faculty and students, there were many key findings provided that allowed better understanding of student dynamics, and the issues that allowed a more comprehensive use of technology and new forms of learning, from digital resources to teaming skills.

Key points that allowed faculty to be successful in the partnership between universities were:

1. Flexibility, consistent communication and investing in the partnership were key.

2. Professor Garduño and Professor Magrane teach different subjects and are on different systems (semester vs quarter) so had to be flexible in creating the content and finding the right timing of a student project - something that would work for both classes. Prioritizing providing students with a fun, unique cross-cultural collaboration experience and then designing it to accommodate content explored as part of both classes was a helpful goal. Faculty invested in learning more about each other, the courses each taught and the students.

As required for both classes, students were evaluated using different grading rubrics on the activities developed during the exercise. Results of the essays 
submitted allowed faculty to verify the impact the activity had on the students. With a more clear understanding of what was expected for them to reflect, students gave clear indications on the following issues:

1. Similarities in the problems they face as a generation and the solutions they can provide given a common ground

2. Importance of technology to facilitate communication between global teams and the consequence of ease to bring them closer, as they face the current COVID-19 lockdown with their own peers

3. Trustful and generous environments in which they can participate, learn and share new ideas as well as understand differences such as language barriers and cultural backgrounds

Faculty members continued to have periodic meetings in order to have their last discussions regarding the activity. These periodic meetings provided a central guideline for the project, as well as the opportunity to share insights found by the students during the activity.

By the beginning of the project, there were a couple of presumed barriers that could set back the activity for the students group:

1. Language barriers: The project was designed for the students to find a common ground in communicating during the 120 minute activity. Even though UP's students are required to be fluent in English as a second language by the end of their senior year, some of the students were still sophomores when the activity took place.

2. Technological differences: Despite being in online classes since March 2020, defining the suitable technological tools from each university and having both groups use them, therefore ensuring access for Google Suite or Zoom Meetings.
The small online environment would prove to result in a dynamic collaboration environment that students would use to explore and share additional features during the whole week. This was a key finding about the collaboration, in which NU students, being more familiar with Zoom, shared and created a whiteboard in which the whole team could visually create together and see how the project looked and was being shaped.

Nevertheless, it was expected as part of the project for the students to come to a solution for communicating with each other during the global teaming activity, and to collaborate to overcome any given technological issue they came across. As a result, students took advantage of:

1. Generational cohort: The students in the project shared an age range between 18 and 22 years old, which allowed them to focus on their similarities rather than their different backgrounds. These included shared experiences during lockdown, such as distance learning, interests in entertainment and sports, and social media usage and knowledge. The icebreaking section of the meeting enabled the students to find common interests and to try to help or understand each other as for example, differences in fluency in English emerged.

2. Design proposals as a generational X-Ray: Each team presented a different design that would solve some of the problems they as a group considered needed to be implemented. The results provided a brief but profound sign of what, as a generation, they see and how both the cultural dimensions play out in this specific assignment, such as care for the environment, education and social issues.

\section{CONCLUSIONS}

Overall this was a successful project and students were enthusiastic in endorsing this collaboration as worth repeating in future Team Dynamics and Adver- 
tising Innovation classes. Some student quotes are included at the end of this document. Themes from what they learned include:

» Students experienced increased confidence in collaborating across cultures in the future and developed more faith in themselves that they can figure out how to navigate future cross-cultural experiences.

» Students were surprised to discover how much they actually had in common despite some cultural differences. Whereas students thought they would experience barriers due to large cultural differences, they discovered that their similarities were stronger and provided points of connection.

» Students were able to apply some of the concepts learned in Team Dynamics to this novel, cross-cultural, virtual teaming experience.

» With regard to language, many NU students experienced humility as the meetings were largely conducted in English and they realized that their colleagues from UP, unlike themselves, were quite fluent in multiple languages. The UP students gained confidence in their English-speaking abilities - they found the NU students to be kind, patient and self-conscious as they communicated in English. Where there was struggle over communicating certain concepts, everyone pitched in to try to understand.

UP students enjoyed, even with previous nervousness, having a bilingual activity that provided them with real-world practice with peers from another university. They valued their own ability to have a meeting in another language, and recognized the importance of having team mates willing to understand and be open to every student at a different pace at speaking English as a second language.
» NU students realized that the UP students were more abreast of US politics and current events than the NU students were aware of the same for Mexico. NU students realized that they could enhance their global perspective.

» UP students were very oriented in having a team discussion in order to decide what ideas would be most useful and have a positive social impact. Even though not every team had the same dynamic, they felt confident expressing themselves and listening to NU students backgrounds to achieve a common concept.

» Having different class objectives, UP students were focused on delivering a clear and viable concept, which was evident in their essays. Students detailed features and the solution they presented both social and cultural contexts, given they found more similarities than differences.

By the end of the teaming activity, students from both Universities were also asked to volunteer to give a video testimonial, with their particular learnings from the activity, impressions from working with international students, and an opinion that summed up their collaboration.

\section{SAMPLE STUDENT QUOTES:}

\section{Northwestern University:}

》

"While I was very strongly apprehensive about the experience and the ability for me to connect with people of possibly a different age, living in a different country, primarily speaking another language, the experience was ultimately a deeply rewarding and innovative experience that not only showed me the skill sets necessary for this type of collaboration, but gave me the confidence that when this type of work comes up again, I will confidently be able to navigate the challenges and hurdles that it might pose." 
" "The most profound lesson I will take away from this experience is definitely that it is really valuable to make connections with others who have diverse backgrounds and perspectives because a lot can be learned from them in a short period of time. Further, while culture is a significant factor, it is not all that makes up identity, so someone who comes from another background can still share a lot of the same interests and have the same abilities."

\section{Universidad Panamericana:}

" "Personally, it seemed like a very good activity, since understanding how someone's creative process works in another university and another career is very important. From this activity I take away that we always have to be patient and open. Not because we do not speak the same language or live in the same environment does not mean that there cannot be some collaboration. Barriers are social constructs that make us think that it is not possible to do certain things in a multicultural team. However, I think this activity proves the opposite."

" "This experience was very good, the truth was that the dynamics of meeting other students from another university outside of Mexico seemed excellent. Our team from the first moment connected in the sense that the conversation started to flow easily. Good communication was the first factor that helped us get started with the creative process, as we were all able to give our points of view and we were all heard. Ideas flowed easily, we sorted very quickly in what we wanted to achieve."

\section{ACKNOWLEDGEMENTS}

This project was supported by an International Classroom Partnering grant from Northwestern University's Office of International Relations and Buffett Institute for Global Affairs. I 